\title{
СОВРЕМЕННЫЙ ПОДХОД К ОБУЧЕНИЮ ИНОСТРАННОМУ ЯЗЫКУ СТУДЕНТОВ ТЕХНИЧЕСКОГО ВУЗА
}

\author{
Батунова И.В., Жавнер Т.В., Лобынева Е.И., \\ Николаева А.Ю.
}

В данной статье авторы рассматривают проблемы англоязычной подготовки в рамках традиционной системы обучения в технических вузах. Также в статье приведен анализ подхода к обучению иностранного языка, представляющего наибольшую практическую трудность в организации учебного процесса. Новизна статьи обеспечивается комплексным подходом к рассматриваемой проблеме, который подразумевает взаимосвязь основных аспектов педагогического прочесса, описьваемого в статье, а именно содержания и средства обучения. Существенное внимание уделено также важности присутствия на занятиях аутентичных материалов, основным источником которых является сегодня Интернет и электронное обучения в системе LMS Moоdle. Выделены положительные стороны и недостатки, мешающие усвоению иностранного языка на современном уровне. Также в результате данной работы авторы внесли предложения по систематизации методов, приемов преподавания, необходимости в изучении языка с использованием современных достижений науки и техники, позволяющей развивать иноязычную коммуникативную компетенщию, играющую положительную роль в современной системе образования.

Цель работь - проанализировать и обосновать необходимость изменения подхода к обучению иностранному языку студентов технического вуза, а также, опираясь на личный опыт, продемонстрировать один из применяемых методов обучения иностранному языку на примере разработанного электронного курса в системе LMS Moodle. 
Метод или методология проведения работы. Основу исследования составляет изучение отечественной литературы, а также метод анализа существуюших методик обучения иностранному языку для выявления и систематизации методов, приемов преподавания с использованием современных достижений науки и техники, позволяющей развивать иноязычную коммуникацию, играющую положительную роль в межкультурной коммуникации.

Результаты. В результате данной работы авторы раскрыли положительные и отрищательные стороны преподавания иностранного языка в неязыковых вузах по традиционной методике. Внесли предложения по систематизации организаџии учебного процесса с помощью электронного курса в системе LMS Moodle.

Область применения результатов. Результаты исследования могут быть востребованы в условиях многоуровневой системы повыпения квалификаџии преподавателей, работающих в технических вузах.

Ключевые слова: межкультурная коммуникация; цели; приемы и методики преподавания; технологии обучения; иностранный язык; электронный курс; системе LMS Moodle.

\section{A MODERN APPROACH TO TEACHING A FOREIGN LANGUAGE TO STUDENTS OF TECHNICAL HIGHER SCHOOL}

\section{Batunova I.V., Zhavner T.V., Lobunova E.I., Nikolaeva A.U.}

In this article, the authors try to consider the problems of English-language training in the framework of the traditional system of education in technical higher school. The article also provides an analysis of the learning approach of the English language, which represents the greatest practical difficulty in organizing the educational process. The novelty of the article is provided by an integrated approach to the problem, which implies the interrelation of the main aspects of the pedagogical process 
described in the article, such as content and means of education. Considerable attention is also paid to the importance of attending authentic materials during the lessons, the main source of which is the Internet and e-learning in the LMS Moodle system. The authors highlighted the positive aspects and disadvantages that hinder the mastery of a foreign language in educational process. As a result, the authors made suggestions on systematization of teaching methods, using modern achievements of science and technology, that allow to develop foreign language communicative competence, which plays a positive role in intercultural communication.

Purpose. The purpose of the work is to analyze and justify the need to change the approach to teaching foreign language in a technical higher I school, and also, based on personal experience, to demonstrate one of the applied methods of teaching foreign language using the example of an e-course in the LMS Moodle system.

Methodology. The base of the research is the study of domestic literature, as well as a comparison method for existing foreign language teaching techniques to reveal and classify methods and techniques for teaching, awarding the educational process by means of modern achievements in sciences and technologies to develop a foreign communicative competence, which plays a great role in cross-cultural communication.

Results. As a result, the authors revealed the positive and negative aspects of teaching a foreign language in a technical higher school by the traditional method. They also made suggestions on systematization of the organization of the educational process due to the electronic course in the LMS Moodle system.

Practical implications. The results of the research can be applied in improving teachers' qualification who works in technical schools.

Keywords: intercultural communication; goals; techniques and methods of teaching; teaching technologies; foreign language; electronic course; LMS Moodle system.

В современном мире все чаще говорят о глобализации и необходимости знания и владения иностранным языком. В следствии чего, мы можем наблюдать изменения, которые претерпевает отечественная 
система образования. Отметим, что эти изменения необходимы, поскольку современные специалисты вынуждены владеть иностранным языком на продвинутом уровне для успешного осуществления своей профессиональной деятельности, вот почему технические вузы все чаще предпринимают меры по реализации алгоритмов, с помощью которых станет возможным повысить уровень владения иностранным языком в рамках высшего профессионального образования. Для достижения цели считаем необходимым совершенствовать и структурировать методы обучения и, конечно же, сам подход к образованию.

На данный момент актуально говорить о компетентностном подходе, как одном из популярных в России, поскольку его можно рассматривать как характеристику соответствия требованиям будущей профессии выпускника технического вуза. Компетентностный подход направлен на комплексное освоение студентами знаний и в первую очередь их практическое применение, что способствует усилению направленности образования, учитывая потребности студента; обучающийся выступает в роли субъекта, который самостоятельно добывает интересующую и необходимую информацию. Именно поэтому, технические вузы должны создавать такие условия, в которых студент увидит свой собственный рост и достижения, будет способен проводить самоанализ, самооценку своей деятельности.

Именно поэтому, сегодня перед преподавателями неязыковых вузов открыты новые возможности на пути совершенствования форм и методов преподавания иностранных языков. Знание иностранного языка выпускниками неязыковых вузов и умение применять его на рецептивном и репродуктивном уровнях является свойством профессиональной компетенции молодого специалиста, соответствующего требованиям времени.

Обучая студентов неязыковых вузов иностранному языку, преподаватель сталкивается с основными проблемами, регулирующими данный процесс, например, постановка задач для выбора методики преподавания и, соответственно им, подбор материала.

Овладение студентами не только умениями и навыками языковой структуры, но также предоставление информации о культурном и 
историческом опыте страны изучаемого языка является значимой целью в преподавании иностранного языка.

Цели обучения многогранны: прежде всего, они определяются потребностями современного общества, исходя из достижений и возможностей социальной деятельности страны, в то же время, они самостоятельно определяют всю систему преподавательской деятельности, в том числе навыки и компетенции, необходимые для совершенствования образовательного процесса студентов неязыковых вузов.

Взаимосвязь, передача и восприятие при помощи языка мыслительной деятельности, являющейся связующим звеном различных процессов и форм современного мира, изменили подход к преподаванию иностранного языка.

Пассов Е.И., Виноградов В.С. и другие исследователи предложили следующие этапы: изучение теории языка, формирование иноязычной речи, умение применять иностранный язык на практике, усовершенствование диалогической речи [Виноградов, 2004].

В данное время существует наработанная специфика преподавания иностранных языков в неязыковых вузах, однако, она должна отвечать всем современным требованиям социального заказа общества.

Предоставление адаптированного программного материала студентам технических специальностей сталкивается с рядом трудностей из-за трансформации в общественных, образовательных функциях, идейных установках. Поскольку очень часто англоязычная подготовка осуществляется в рамках традиционной системы обучения, она оказывается недостаточной для решения проблемы заинтересованности в изучении языка на сознательном уровне, понимания необходимости применения его как в профессиональной среде, так и в повседневном общении. Затруднения объясняются традиционной методикой и практикой организационных форм обучения иностранному языку. Способ инклюзии современных образовательных педагогических технологий в содержание учебных программ, а именно информационно-коммуникационных методик, которые являются одним из выходов в преодолении сложившихся трудностей [Жавнер, Воног, Адольф, 2016, с. 246]. 
Усвоение теории иностранного языка, правил пользования лексическими единицами речи, а также собственно процесс пользования иностранным языком, т.е. общение на иностранном языке с носителем другой культуры есть не что иное, как межкультурная (кросскультурная) коммуникация. От уровня владения иностранным языком, от степени развитости иноязычной коммуникативной компетенции зависят основные характеристики межкультурной коммуникации. Несовершенное владение грамматическими конструкциями кардинально не мешает межкультурной коммуникации с носителем языка, так как он может без особого труда понять главное в высказывании иностранца, не компетентного в построении предложения, на что указывают примеры межкультурной коммуникации. Справедливость данного тезиса подтверждается многочисленными примерами из практики реальной межкультурной коммуникации [Барышников, 2012].

Коммуникативная компетентность студентов в профессиональных межкультурных отношениях будет сформирована только при условии качественного усвоения программного материала предмета «Иностранный язык», установленного федеральным государственными стандартами высшего образования. Это дает возможность использовать различные направления подготовки, как в формировании компетентности, так и в мотивации заинтересованности в изучении иностранного языка не только делая упор на освоение лексики по специальности, а изучать язык более разносторонне, что сформирует межкультурную коммуникацию на более высоком уровне, отвечающем основным целям, определяющем направленность предмета «иностранный язык» [Жавнер, 2016, с. 40].

Современные способы и приемы обучения иностранным языкам, включающие использование мультимедийных средств в процессе преподавания - аудио- и видеотехники, обучающих компьютерных программ, применение интерактивных учебных курсов отвечает поставленным целям в выполнении задач обучения иностранному языку, способствует выбору наиболее современных способов и приемов, используя медийные средства, дающие возможность по- 
лучить представление о стране, ее традициях и т. д., пообщаться с носителями изучаемого языка [Антышев, 2012].

Наиболее эффективное использование методов, приемов и способов организации коммуникативного общения возможно при условии их систематизации. В отведенное количество часов аудиторной и самостоятельной работы студент должен научиться профессионально и автономно управлять процессами обучения на основе дидактического материала, используя современные технические средства обучения.

При формировании общения в профессиональной области знание лексики и грамматических форм языка имеет важное значение [Барышников, 2012].

Предлагая студентам аутентичные тексты профессиональной направленности для изучения лексики и грамматических форм иностранного языка, учебная программа дает им возможность продолжить обучение в магистратуре или аспирантуре, общаться с иностранными коллегами в профессиональной области. При этом необходимо формировать у студентов навыки общения.

Астахова Е.А. считает, что, формируя навыки общения, необходимо помнить о значимости видов речевого взаимодействия, коммуникативные интенции собеседников реализовать вариативно, не забывать о тактике и стратегии речевого поведения. Обучая межкультурному общению, выделяя коммуникативные ситуации необходимо сопоставлять с видами прагматической функции речевых средств, для определения которой используются соответственные речевые намерения и речевые акты.

Она выделяет следующие типы коммуникативных ситуаций: умение вести беседу и прекратить ее по этическим нормам (в диалоге - поддержание и разъединение контакта) с одним, несколькими или группой собеседников, активизировать информационную деятельность в деловой или общекультурной обстановке, проявление чувств соответственно информации, руководство поведенческими нормами партнеров, мотивация результативного взаимодействия.

В неязыковых вузах в программы по изучению иностранного языка необходимо включать систематизированные учебные мате- 
риалы по лингвострановедческой тематике, культуре общения, способствующие разнообразить коммуникативные навыки всесторонне развитых специалистов.

К сожалению, между школой и вузом преемственности нет, к тому же, в неязыковые вузы поступает достаточное количество абитуриентов со слабой языковой подготовкой, преподаватель имеет дело с группами студентов с разным уровнем подготовки, что приводит к неравному усвоению материала.

Также, в программах по изучению иностранного языка в неязыковых вузах должны содержаться дополнительные систематизированные учебные материалы по лингвострановедческой тематике, культуре общения с целью расширить коммуникативные возможности будущих специалистов.

Исходя из вышесказанного, важно отметить, что возникает необходимость разработки таких учебных программ для студентов неязыковых специальностей, которые бы позволили обучить их профессиональному умению строить разговорную речь на основе взаимодействия различных подходов и методов обучения на материалах качественных аутентичных образовательных средств.

В неязыковом вузе иностранный язык не ставится «во главу угла», наибольшее количество часов отдается традиционно предметам инженерной специальности. При таком соотношении количества часов по иностранному языку и профилирующим предметам коммуникативная цель не будет достигнута в полном объеме. В связи с чем, основная цель не может быть достигнута. Для того, чтобы расширить кругозор студентов, повысить их общий культурный уровень, что в свою очередь, повысит значимость самостоятельной работы студентов и обуславливает создание такого пакета заданий, выполнение которых требует использования личного компьютера, то есть, мы акцентируем внимание не на аудиторную работу, а на внеаудиторную самостоятельную - работу в домашних условиях. В свою очередь, аудиторная работа будет служить в качестве подготовительного этапа к самостоятельному выполнению заданий, которые могут включаться непосредственно в электронный курс по иностранному языку. 
Что и заставляет нас пересмотреть и переосмыслить существующую структуру и применяемые технологии в образовательном процессе. Считаем, что одним из перспективных направлений является электронное образование, которое будет максимально соответствовать и отвечать потребностям и целям современного образования. Одним из преимуществ электронного обучения является работа с внушительным объемом информации, способность ее анализировать за ограниченное количество времени. Не оспоримым фактом считаем и то, что благодаря электронному обучению заинтересованные в получении знаний лица уже виртуально взаимодействуют друг с другом, стимулируя тем самым развитие дистанционного, мобильного образования.

В качестве решения выше поставленных нами задач, хотелось бы предложить один из существующих современных методов преподавания как разработка электронных курсов в системе LMS Moodle (Modular Object - Oriented Dynamic Learning Environment (модульная объектно - ориентированная динамическая обучающая среда), который активно и эффективно применяется в Сибирском федеральном университете. Данный метод уже прошел апробацию и внедрен в систему обучения вуза.

Говоря об эффективности применения данного курса, в первую очередь необходимо отметить, что LMS Moodle - это свободная система управления обучением, ориентированная, прежде всего, на организацию непрерывного взаимодействия между преподавателем и студентами. Используя данный электронный курс, преподаватель может создавать курсы самостоятельно, наполняя их содержимым в виде текстов, вспомогательных файлов, презентаций, опросников, тестов, видео файлами и т.п. Для использования Moodle достаточно иметь web-браузер, что делает использование этой учебной среды удобной как для преподавателя, так и для обучаемых. Таким образом, преподаватель может прослеживать не только выполнение учениками заданий, но и выставлять оценки и давать комментарии. Таким oбразом, Moodle является и центром создания учебного материала и обеспечивает интерактивное взаимодействие между участниками учебного процесса. 
Данная система имеет удобный интуитивно понятный интерфейс. Преподаватель самостоятельно, прибегая только к помощи справочной системы, может создать электронный курс и управлять его работой: вставлять таблицы, схемы, графику, видео, флэш, загружать дополнительную учебно-методическую литературу для обучающихся и др. Огромным преимуществом данного курса считаем и то, что в него включены такие элементы как: лекция, задание, форум, глоссарий, wiki, чат и т.д.

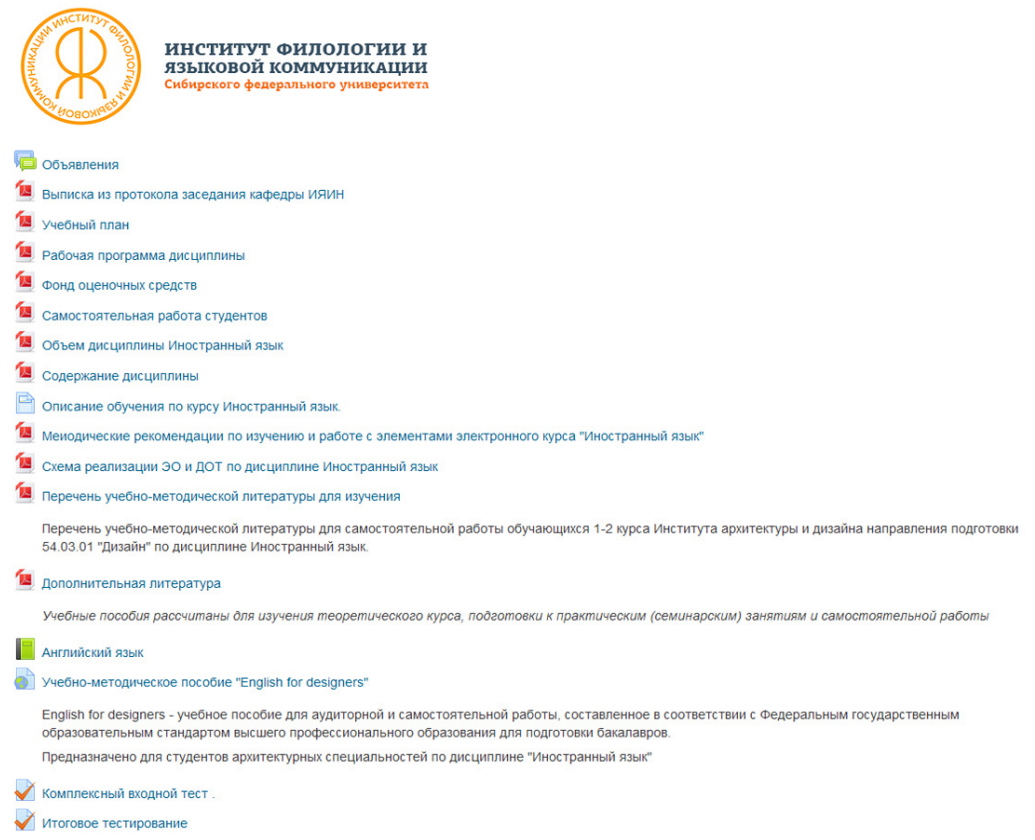

Рис. 1. Главная страница электронного курса «Иностранный язык»

Современная система управления обучением Moodle обладает и большим набором средств коммуникации: электронная почта и обмен вложенными файлами между преподавателем и студентами, форум, чат, обмен личными сообщениями, ведение блогов как на русском, так и на иностранном языке, проведение web-конференций с участниками образовательного процесса. 
Поскольку дисциплина «Иностранный язык» является практической, представленный ниже разработанный электронный курс играет роль поддержки к реализуемой дисциплине, с целью обеспечения студентов дополнительными учебно-методическими материалами к самостоятельной работе, для проработки практических занятий и совершенствования своих знаний, умений и навыков (рис. 1).

Работа с курсом для студентов начинается с подробного, поэтапного описания электронного курса. Также представлен большой раздел, посвященный методическому обеспечению курса, куда входит полный комплект документов по реализуемой дисциплине: рабочая программа дисциплины, план профиля обучения, методические рекомендации к изучению дисциплины, схема реализации ЭО и ДОТ, технологическая карта дисциплины и фонд оценочных средств по дисциплине. На главной странице также можно найти учебно-методические материалы по дисциплине «Иностранный язык», дополнительная литература, где находятся все необходимые учебные пособия, материалы и словари, требующиеся для освоения студентами данного курса и выполнения, как практических заданий, так и самостоятельных работ.

Модуль 1 Учебно- позновательная, социально- культурная сфера общения

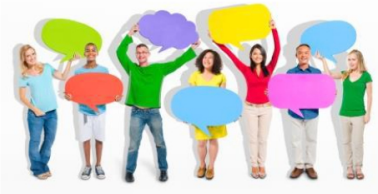

Модуль 2. Деловая сфера коммуникации

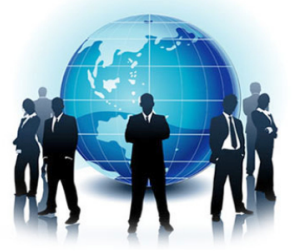

Рис. 2. Модули электронного курса «Иностранный язык» 
Курс представлен в виде 4 укрупненных модулей (рис. 2) и разделов по темам (рис. 3), которые полностью соответствуют рабочей программе дисциплины.

\section{Unit 9 . Design}

Данный раздел выполняется учащимися 2 курса 4 семестра.

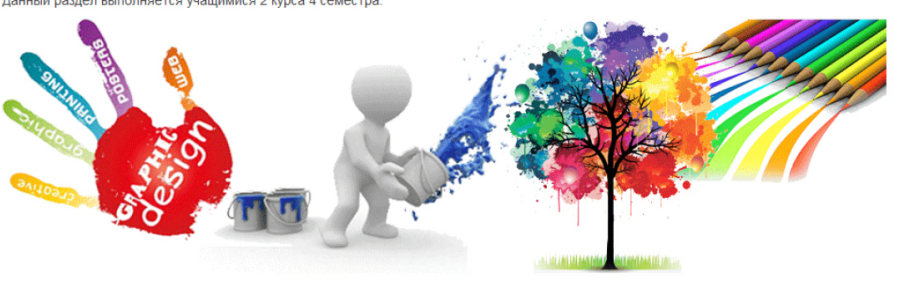

'巡 Модуль 3 Unit 9 - Lesson 1

Практическое занятие: Модуль 3. Unit 9 - Lesson 1

Lead-in. Work in pairs and answer the questions:

1) Do you know any intermational furniture companies?

2) Do you like the furniture that they produce?

3) What is the most famous furniture company in your country?

(1.) Самостоятельная работа: Presentation "Commercial Fumiture Manufacturing" Модуль 3, Unit 9 Lesson 1

Use the Internet and write 8-10 sentences about a famous furniture manufacture.

Рис. 3. Разделы и подразделы электронного курса «Иностранный язык»

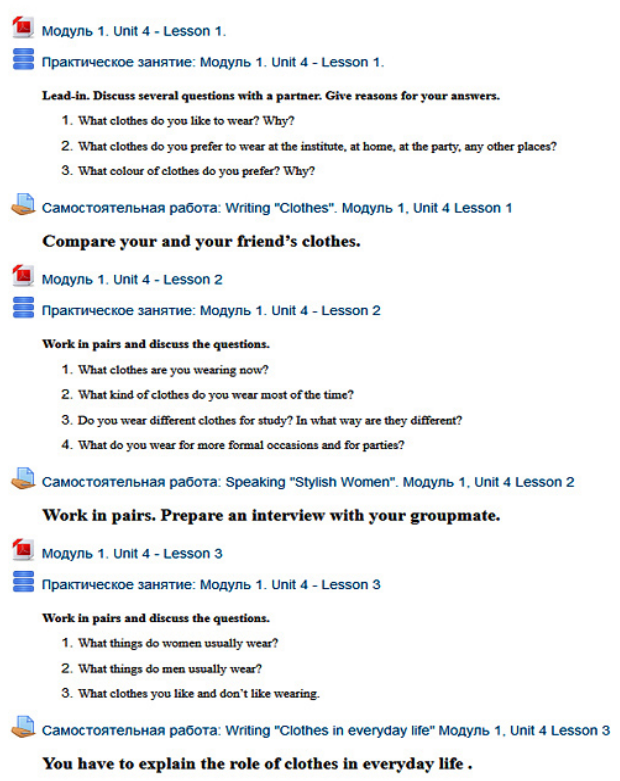

Рис. 4. Пример использованных элементов в ЭК «Иностранный язык» 
В разделах студент может найти полное описание заданий, методические рекомендации и пояснения к выполнению конкретного типа задания.

При разработке электронного курса использовались такие элементы LMSMoodle как: задание, страница, файл (рис. 4).

Таким образом, можно сделать вывод, что качественное усвоение английского языка в неязыковых вузах должно быть обусловлено общими задачами содержания, методов, средств, а также образовательной деятельностью в сфере языковой практики и гармоничной совместной работой в учебном коллективе. Следует развивать у студентов интерес к самостоятельной работе, способности самоконтроля, умение оценивать собственную деятельность в процессе обучения и по окончании изучения программного материала, используя разные виды контроля преподавателем, предоставить студентам и преподавателям материалы из разных информационных источников: Интернет-ресурсы, сведения из Российских и международных источников - новейших методических разработок, энциклопедических изданий, словарей различной тематики, с сайтов с материалами профессионального содержания по языку, развивать социокультурные знания. Все эти способы помогут выполнить цели и задачи, представленные социальным заказом общества к специалистам технических специальностей, в том числе на площадке электронного курса.

\section{Список литературы}

1. Астахова Е.А. Прагматическая и социокультурная обусловленность речевых умений студентов языков языкового вуза [Электронный ресурс] / Ставрополь, 2012. URL: http://lib.znate.ru/docs/index-229815. html (дата обращения: 23.08.2018).

2. Батунова И.В. Процесс обучения иностранному (английскому) языку в неязыковых вузах / И.В. Батунова // Международный научноисследовательский журнал. 2017. № 01 (55) Часть 3. С. 25-27. URL: https://research-journal.org/pedagogy/process-obucheniya-inostrannomuanglijskomu-yazyku-v-neyazykovyx-vuzax/ (дата обращения: 23.08.2018). doi: 10.23670/IRJ.2017.55.035 
3. Батунова И.В., Лобынева Е.И., Николаева А.Ю. Применение эффективных методов обучения на занятиях по иностранному языку в неязыковых (технических) вузах / И.В. Батунова, Е.И. Лобынева, А.Ю. Николаева // Международный научно-исследовательский журнал. 2018. № 1 (67) Часть 4. C. 11-14. URL: https://research-journal.org/ pedagogy/primenenie-effektivnyx-metodov-obucheniya-na-zanyatiyaxpo-inostrannomu-yazyku-v-neyazykovyx-texnicheskix-vuzax/ (дата обращения: 23.08.2018). doi: 10.23670/IRJ.2018.67.045

4. Барышников Н.В. Теоретические и практические аспекты преподавания иностранных языков и культур в различных условиях [Электронный ресурс] / Н.В. Барышников, Пятигорск 2012. URL: http:// lib.znate.ru/docs/index-229815.html_(дата обращения: 23.08.2018).

5. Виноградов В.С. Введение в переводоведение «общие и лексические вопросы» [Электронный ресурс] / В.С. Виноградов, Москва, 2004. URL: http://linguistic.ru/index.php?id=88\&op=content_(дата обращения: 23.08.2018).

6. Воног В.В., Прохорова О.А. Использование LMS MOODLE при обучении иностранному языку в аспирантуре в рамках смешанного и дистанционного обучения // Вестник КемГУ, Выпуск 2 (62). Т. 3. г. Кемерово, 2015. С. 27-30.

7. Жавнер Т.В. Формирование профессиональной межкультурной коммуникативной компетенции студентов инженерных направлений подготовки при смешанном обучении на базе электронной платформы // Вестник КГПУ им. В.П. Астафьева. 2016. № 4 (38). С. 39-43.

8. Мусина М.К. Коммуникативный подход в обучении иностранным языкам в неязыковом вузе. URL: http://www.rusnauka.com/9_SNP_2015/ Philologia/7_190159.doc.htm (дата обращения: 23.08.2018).

9. Швалова Г.В. Формирование мотивации студентов технического вуза при изучении профессионального иностранного языка // Научно-методический электронный журнал «Концепт». 2012. №11 (15). URL: https://e-koncept.ru/2012/12152.htm (дата обращения: 23.08.2018).

10. Common European Framework of Reference for Languages: Learning, teaching, assessment. Cambridge: Cambridge University Press, 2007 (9th printing). 260 p. URL: https://www.coe.int/t/dg4/linguistic/source/ framework_en.pdf (дата обращения: 22.09.2018). 
11. Educational Excellence Everywhere. Presented to Parliament by the Secretary of State for Education by Command of Her Majesty. L.: Department for Education, 2016. P. 123.

12. Justi R.S., Gilbert J.K. Modelling, teachers' views on the nature of modelling, and implications for the education of modellers / R.S. Justi, J.K. Gilbert // International Journal of Science Education. 2002. № 24-4, pp. 369-387. URL: http://dx.doi.org/10.1080/09500690110110142 (дата обращения: 22.09.2018).

13. Lusi Nurhayati, M.App.Ling. (TESOL), Nury Supriyanti TEFL Methodology Teaching English as Foreign Language Methodology / Lusi Nurhayati, M.App.Ling. (TESOL), Nury Supriyanti // Jurusan Pendidikan Bahasa Inggris Fakultas Bahasa dan Seni Universitas Negeri Yogyak arta. 2008. P. 50.

14. Sandra Attard Montalto. The CLIL Guidebook [Electronic resource]/ A. Montalto, L. Walter, M. Theodorou, K. Chrysanthou // Lifelong Learning Program. 2015. URL: https:/www.goethe.de/en/spr/unt/kum/ $\mathrm{clg} / 20782495 . \mathrm{html}$ (дата обращения: 22.09.2018).

\section{References}

1. Astakhova E.A. Pragmaticheskaja I coziokulturnaja obuslovlennoct rechevih umenij ctudentov jasikov jasikovih vusov [Pragmatic and sociocultural conditionality of students' languages speaking skills in the language university]. Stavropol, 2012. URL: http://lib.znate.ru/docs/index-229815.html (accessed: 23.08.2018) [in Russian].

2. Batunova I.V. Process obucheniya inostrannomu (anglijskomu) yaziku v neyazykovyh vuzax [The process of teaching foreign (English) language in non-linguistic universities]. Ekaterinburg, 2017. № 01 (55) Part 3, pp. 25-27. https://research-journal.org/pedagogy/process-obucheniya-inostrannomu-anglijskomu-yazyku-v-neyazykovyx-vuzax/ (accessed: 23.08.2018). [inRussian]. doi: 10.23670/IRJ.2017.55.035

3. Batunova I.V., Lobinova E.I., Nikolaeva A.U. Primenenie effektivnyx metodov obucheniya na zanyatiyax po inostrannomu yazyku $v$ neyazykovyx texnicheskix vuzax [Application of effective teaching methods in foreign language classes in non-linguistic (technical) universities]. 
Ekaterinburg, 2018. № 1 (67), Part 4, pp. 11-14. https://research-journal.org/pedagogy/primenenie-effektivnyx-metodov-obucheniya-na-zanyatiyax-po-inostrannomu-yazyku-v-neyazykovyx-texnicheskix-vuzax/ (accessed: 23.08.2018). [in Russian]. Doi: 10.23670/IRJ.2018.67.045

4. Barishnikov N.V. Teoreticheskie I prakticheskie aspecti prepodavaniya inostrannih yazykov $i$ kultur $v$ razlichnix usloviyax [Theoretical and practical aspects of teaching foreign languages and cultures in different conditions]. Pyatigork, 2012. http://lib.znate.ru/docs/index-229815.html (accessed: 23.08.2018) [in Russian].

5. Vinogradov V.S. Vvedenie v perevodovedenie "obshie i leksicheskie voprosi" [Introduction to the translation of «general and lexical questions»]. Moscow, 2004. URL: http://linguistic.ru/index.php?id=88\&op=content (accessed: 23.08.2018) [in Russian].

6. Vonog V.V., Prokhorova O.A. Ispolzovanie LMS MOODLE pri obucheni inostrannomu yaziku $v$ aspiranture $v$ ramkax smeshannogo $i$ distanzionnogo obucheniya [Using LMS MOODLE in teaching a foreign language in post-graduate school in the framework of mixed and distance learning]. Kemerovo, 2015, pp. 27-30. [in Russian].

7. Zhavner T.V. Formirovanie mezhkul'turnoj professional'noj kommunikativnoj kompetencii studentov inzhenernyh napravlenij podgotovki s primeneniem jelektronnoj platformy pri smeshennom obuchenii [Formation of intercultural professional communicative competence of engineering students with the use of an electronic platform with mixed training]. Vestnik Krasnojarskogo gosudarstvennogo pedagogicheskogo universiteta im. V.P. Astaf'eva [Bulletin of the Krasnoyarsk State Pedagogical University after V.P. Astafyev]. 2016, pp. 39-43. [in Russian].

8. Musina M.K. Kommunikativni podhod v obuchenii inostrannim yasikam $v$ neyasikovom vyse [Communicative approach in teaching foreign languages in a non-linguistic universities]. http://www.rusnauka.com/9 SNP_2015/Philologia/7_190159.doc.htm (accessed: 23.08.2018) [in Russian].

9. Shvalova G.V. Formirivanie motivacii stidentov tehnicheskogo vusa pri isuchenii professionalnovo inostrannogo yasika [Motivation formation of technical institute students in the studying of professional foreign lan- 
guage]. Koncept. 2012. №11 (15). https://e-koncept.ru/2012/12152.htm (accessed: 23.08.2018) [in Russian].

10. Common European Framework of Reference for Languages: Learning, teaching, assessment. Cambridge: Cambridge University Press, 2007 (9th printing). 260 p. https://www.coe.int/t/dg4/linguistic/source/framework_en.pdf (accessed: 22.09.2017) [in English].

11. Educational Excellence Everywhere. Presented to Parliament by the Secretary of State for Education by Command of Her Majesty. L.: Department for Education, 2016. P. 123 [in English].

12. Justi R.S., Gilbert J.K. Modelling, teachers' views on the nature of modelling, and implications for the education of modellers. International Journal of Science Education. 2002. № 24-4, pp. 369-387. http://dx.doi. org/10.1080/09500690110110142 (accessed: 22.09.2017). [in English]

13. Lusi Nurhayati, M.App.Ling. (TESOL), Nury Supriyanti TEFL Methodology Teaching English as Foreign Language Methodology / Lusi Nurhayati, M.App.Ling. (TESOL), Nury Supriyanti. Jurusan Pendidikan Bahasa Inggris Fakultas Bahasa dan Seni Universitas Negeri Yogyak arta. 2008. P. 50 [in English].

14. Montalto A., Walter L., Theodorou M., Chrysanthou K. The CLIL Guidebook. Lifelong Learning Program. 2015. https://www.goethe.de/en/spr/ unt/kum/clg/20782495.html (accessed: 22.09.2018) [in English].

\section{ДАННЫЕ ОБ АВТОРАХ:}

Батунова Ирина Валерьевна, доцент кафедры иностранных языков для инженерных направлений Института филологии и языковой коммуникации, кандидат педагогических наук Сибирский Федеральный Университет пр. Свободный, 79, г. Красноярск, 660041, Российская Федераџия familiya_irina@mail.ru

Жавнер Татьяна Владимировна, старший преподаватель кафедры иностранных языков для инженерных направлений Института филологии и языковой коммуникации Сибирский Федеральньй Университет 
пр. Свободный, 79, г. Красноярск, 660041, Российская Федераџия sttanya82@mail.ru

Лобынева Екатерина Ивановна, доцент кафедры иностранных языков для инженерных направлений Института филологии и языковой коммуникации, кандидат культурологии Сибирский Федеральный Университет пр. Свободный, 79, г. Красноярск, 660041, Российская Федераџия katrin1505@mail.ru

Николаева Альбина Юрьевна, доцент кафедры иностранных языков для инженерных направлений Института филологии и языковой коммуникации, кандидат исторических наук Сибирский Федеральный Университет пр. Свободный, 79, г. Красноярск, 660041, Российская Федераџия space1120@yandex.ru

\section{DATA ABOUT THE AUTHORS}

Batunova Irina Valerievna, Associate Professor at the Department of the Department of Foreign Languages for Engineering Areas Students of the School Of Philology and Language Communication, $\mathrm{PhD}$ in Pedagogy

Siberian Federal University

79, Svobodnii pr., Krasnoyarsk, 660041, Russian Federation familiya_irina@mail.ru

ORCID: 0000-0002-1825-0097

Zhavner Tatyana Vladimirovna, Senior Lecturer, Department of the Department of Foreign Languages for Engineering Areas Students of the School Of Philology and Language Communication Siberian Federal University

79, Svobodnii pr., Krasnoyarsk, 660041, Russian Federation sttanya82@mail.ru

ORCID: 0000-0002-1617-715 
Lobyneva Ekaterina Ivanovna, Associate Professor at the Department of the Department of Foreign Languages for Engineering Areas Students of the School Of Philology And Language Communication, $\mathrm{PhD}$ in Culture Studies

Siberian Federal University

79, Svobodnii pr., Krasnoyarsk, 660041, Russian Federation katrin1505@mail.ru

ORCID: 0000-0002-4053-175X

Nickolaeva Albina Urievna, Associate Professor at the Department of the Department of Foreign Languages for Engineering Areas Students of the School Of Philology and Language Communication, $\mathrm{PhD}$ in Historical Sciences

Siberian Federal University

79, Svobodnii pr., Krasnoyarsk, 660041, Russian Federation space1120@yandex.ru

ORCID: 0000-0003-2060-6344 